\title{
HABITAR Y CONSTRUIR: EMANCIPACIÓN Y CATÁSTROFE ${ }^{1}$
}

\author{
Alejandro Marco Madrid Zan²
}

\section{Resumen/Abstract}

Sin duda, la reflexión sobre el construir y el habitar no interesa sólo a la arquitectura. Para la filosofía, la reflexión sobre el habitar ocupa un lugar primordial en cuanto modo de existencia de lo humano, más allá de todo humanismo. Implica, en sentido amplio, una reflexión sobre el ahí del ser-ahí, sobre el espacio, el lugar y el tener lugar. Significa, a la vez, pensar el estar, pensar la técnica y la política, la producción y la economía. Pensar no exento de ambigüedad, entre la promesa de emancipación y la catástrofe.

DWELL AND BUILD: EMANCIPATION AND CATASTROPHE

Undoubtedly, reflection on building and living does not only concern architecture. For philosophy, reflection on dwelling occupies a primordial place as a mode of existence of the human, beyond all humanism. It implies, in a broad sense, a reflection on the thereof beingthere, about space, place and place. It means, at the same time, to think about being, thinking about technology and politics, production and economy. To think not free of ambiguity, between the promise of emancipation and the catastrophe.

\footnotetext{
${ }^{1}$ El presente artículo de Alejandro Madrid Zan se inserta en el marco del proyecto APIX-13 /17 de la Universidad Metropolitana de Ciencias de la Educación, 2017. Corresponde al desarrollo del proyecto de investigación sobre "Guerra, espacio y soberanía", de este autor, desarrollada en el Departamento de Filosofía.

${ }^{2}$ Chileno, Universidad Metropolitana de Ciencias de la Educación (UMCE). E-mail: madridzan@gmail.com
} 
"Los árboles son sillas y mesas que se mecen con el viento" Nicanor Parra

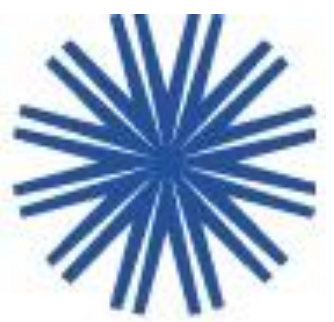

Diremos, antes que nada, que la presentación de esos textos debe comenzar por situarlos respecto de nosotros, de un nosotros que nos parece configura algo así como lo propio de la reflexión, en cuanto lo propio alude a su vez a la identidad. Por una parte, queremos señalar con esto, como antes lo hicieran otros -Luis Oyarzún, Patricio Marchant pueden ser mencionados como referentes en este caso- hacia un problema fundamental: cómo olvidar que la recepción de una tradición filosófica, así como de cualquier traza cultural y, desde luego, arquitectónica, nos implica a nosotros en cuanto lectores e intérpretes chilenos y latinoamericanos, olvidar el tiempo y lugar que condicionan esa recepción. Entendemos así que cuando hablamos de la recepción de un pensamiento, de una tradición o cultura, esa recepción tiene lugar, se apropia, justamente, en y para ese nosotros que constituye y se constituye como el sujeto de esa reflexión. Pues es ese nosotros aquello que da lugar a la reflexión, y dando lugar la hace propia. Sin duda no se trata simplemente de reivindicar con esto nuestra identidad como si ésta fuese una cosa ganada: ¿cómo podríamos definir desde ya lo propio en nuestra reflexión? Y ¿cómo definir, por otra parte, ese topo en que intentamos establecer un lugar para la reflexión o ese lugar nuestro en el que decimos que se da lugar a la reflexión? ¿En qué consiste el lugar, o el espacio, desde el cual y en el cual nosotros, chilenos o americanos recibimos, acogemos, interpretamos, traducimos y situamos a una tradición? Ciertamente cuando aludimos al espacio no se trata de determinar una pura cuestión "objetiva" que remitiría a cierta "exterioridad espacial” -el territorio continental o la "delgada faja" en cuanto quantum material; tampoco, cuando aludimos al sujeto, pretendemos referirnos a una forma de la subjetividad que pudiésemos definir en términos de una "identidad substancial". Podemos decir, por el contrario, que se trata más bien de una identidad que no significa pura permanencia; pues esa identidad no es una "cosa" espacial o extensa, sino más bien una imagen de identidad que permite justamente articular la 
temporalidad constituyendo, más que un desde aquí, un desde ya. Así, al preguntarnos qué es lo que nos constituye como sujetos americanos, por aquello que articula este suelo americano en cuanto continuidad, pareciera primeramente que referirse al suelo americano fuese antes que nada un nombre para una conjunción de huellas de lo imaginario, algo que permite nombrar no un territorio, sino una andadura o un trazado en el que intentamos leer la huella de lo Uno en medio de la diseminación de lo múltiple. Pues pareciera que esa identidad de sujeto no alude a una substancia, ni tampoco a una verdad original u originaria, sino que se constituye como la identidad de la huella o inscripción a través de un trazado temporal. Identidad que en cuanto identidad de una comunidad a través del tiempo quizás sólo pueda ser pensada como una identidad tal como la que articula el mito: como lo recuerda Jean-Luc Nancy, quizá sólo el mito articule el fundamento de una comunidad, quizás sólo el mito funde finalmente el nosotros en el que la reflexión puede tener lugar. El mito, narración que, sin ser historia, permite la historia. Para Nancy, el mito fundaría la comunidad estructurándola a través de su remisión a un origen común: la humanidad se encontraría “estructurada por su relación con sus mitos" ya que el mito "es de origen o del origen, remite a una fundación mítica, y él mismo funda (una conciencia, un pueblo, un relato) a través de ésta remisión.” (Nancy, 2001, p. 84) Chilenos y americanos, son nombres que mientan ese nosotros en cuanto lugar en el que desde ya articulamos la recepción de cualquier tradición política, filosófica, arquitectónica. Sin que tengamos que evocar otro suelo sino esa precomprensión que sin embargo sólo podemos invocar como origen mítico. Origen las más de las veces vago, fluctuante e inconsciente que le confiere una identidad a ese suelo que constituye ese lugar desde donde hablamos, interpretamos, traducimos y que se articula como nuestro lugar.

Al hablar del mito sabemos que es imposible intentar restituir el fundamento mítico de las culturas pre-colombinas. Sin duda, la imposición de la Palabra bíblica constituye el momento de la refundación de las comunidades americanas en torno a un nuevo concepto de humanidad que se impone a todas las ellas: la evangelización que impone y justifica la conquista de América es nuestro primer contacto con la "globalización". Un código se impone, un meta discurso fundacional que permite articular el orden occidental a partir de un único mito, consagrado como la Palabra o el Verbo. Ese concepto que articula el mito bíblico 
$\overline{\text { es también, y fundamentalmente, un nuevo concepto del tiempo, en cuanto todo relato, toda }}$ constitución de discurso y proyecto se encuentra a partir de allí fundado y referido finalmente a la temporalidad que impone ese meta-discurso fundacional. Esa temporalidad nos constituye, ambiguamente, entre la pertenencia a esa Palabra presente y el olvido de las palabras que afirmaban la pertenecía al antiguo mundo americano. Ese concepto de tiempo que se impone desde allí es el tiempo de la Historia.

Así, parece imposible pensar en nuestra identidad e intentar desembarazarse, o “evitar”, ese fundamento mítico impuesto por la conquista, en cuanto el concepto mismo de Historia remite, en última instancia, a ese mito fundacional que en ella se trasmite. Aparentemente, nuestra pre comprensión de lo que significa el hombre y de lo que significa el habitar no puede sino ser enunciada desde allí. El mito bíblico que impone a América la conquista describe el origen de lo humano como separación, escisión, ruptura. Separación de hombre y mundo, separación de Naturaleza e Historia: lo constitutivo de lo humano sería esa primera y definitiva distancia entre sujeto y mundo que la narración o el relato genético identifica con el surgimiento de la conciencia. En la imagen del Génesis, el hombre irrumpe violentamente en el mundo dando comienzo a la Historia a partir de esa transgresión primera y original en que adquiere el conocimiento y por la cual es arrojado hacia el afuera, arrojado al mundo. El ex-istere latino alude, justamente, a esta expulsión violenta hacia el exterior. Así, el mito del origen que heredamos a través de esa imagen bíblica y que describe la aparición del Hombre a través de los conceptos fundamentales de caída y separación, trabajo y redención, instaura e impone desde allí, antes que nada, esta nueva concepción del tiempo, el tiempo histórico. A través de éste la interpretación cristiana transmite e impone la concepción una temporalidad lineal y progresiva: en el relato mítico se determina un origen -la falta originaly un fin -la redención de las almas: sólo desde allí podemos comprender el origen de la idea de progreso histórico que impera en los distintos proyectos políticos que nos transmite luego Occidente: el progreso hacia la redención de las almas, con la conquista y colonia; el progreso desde el estado teológico y metafísico hacia el estado positivo entendido como edad adulta de la humanidad, proyecto que se encarna en el ideal liberal republicano, o el progreso hacia la liberación del trabajo y la conquista de una sociedad sin clases presente en el discurso socialista: la teleología lineal y la idea de progreso que inaugura el texto bíblico preside la 
concepción del tiempo y la Historia presente en los distintos proyectos que caracterizan a la modernidad, de Comte a Marx. La Conquista, realizada con la espada en una mano y el Libro sagrado en la otra, instaura un orden que inserta a todas las comunidades latinoamericanas en una temporalidad lineal, inscribiendo desde entonces en nuestra cronología ese alfa y omega, respecto del cual referimos nuestra data: 2005 fecha que regula nuestra cotidianeidad desde ese punto alfa que es la Natividad.

El tiempo que nos transmite el mito es el tiempo de un hombre descrito como ser arrojado al mundo, separado de la naturaleza y enfrentado a una temporalidad que se revela, antes que nada, como pro-yección de su ser en el futuro. El tiempo del hombre en cuanto ser caído y arrojado en el mundo se revela antes que nada en cuanto anticipación de futuro y como necesidad. Proyecto del hombre que, en cuanto mortal, consciente de su finitud, proyecta su ser hacia el futuro en el modo de la pre-ocupación -de la "cura" o la "incuria", para emplear los términos que se han utilizado para traducir a Heidegger. Rompiendo la relación inmediata con el mundo, el surgimiento de la conciencia instaura una definitiva mediación en esa relación. Mas la conciencia de la finitud no surge solamente como una pura representación ideal, sino como conciencia de una necesidad: así, su existencia en cuanto existencia esencialmente mediata; supone una relación con el entorno que se manifiesta como preocupación, a la vez, como trabajo -transformación, producción- que cobran sentido a partir de la conciencia de su finitud. "La civilización del trabajo y de la posesión surge en su totalidad como concretización del ser separado efectuando su separación”, dirá Levinas (1992, p.163). Conciencia y trabajo como pro-yección de su ser en la pura negatividad del futuro. Conciencia y trabajo como aspectos de esta pre-ocupación fundamental que surge de la conciencia de la finitud, como pre-visión de aquello que está por-venir. En el Paraíso Perdido de Milton, el hombre y la mujer, echando una última mirada hacia lo que abandonan, enjugan sus lágrimas y, mirando el amplio horizonte que se abre ante sus ojos, se disponen a trabajar. Para el mundo protestante, la caída es antes que nada el comienzo del trabajo, entendido como trabajo de redención. El mito adánico es el mito de la interrupción de la inmortalidad entendida como esa temporalidad cíclica y circular de un ser en armonía con la naturaleza -el mito de la unidad perdida; la inmortalidad edénica es la inmortalidad de la existencia natural que supera a la muerte subsistiendo en la cadena infinita y circular de la 
$\overline{\text { reproducción de las especies. La falta original que interrumpe esa inmortalidad de la }}$ existencia inmediata es para el hombre conciencia de su finitud. Al mismo tiempo, la conciencia de su propia finitud es también para el hombre, según esta tradición, el origen del Tiempo, en cuanto la Caída, el inicio de la separación, es el comienzo del tiempo concebido como tiempo de la Historia. ${ }^{3}$ El concepto mismo de existencia alude a ese salto hacia el afuera mentado en el ex-istere, el hombre en tanto pro-yecto, imagen de sí lanzada hacia el futuro en cuanto pro-yección. Proyección en la que el hombre erige su propia subjetividad inscribiéndola en la pura negatividad del futuro proyectado, ese futuro que le pre-ocupa en tanto ente mortal y finito.

En el relato mítico, el saber es inmediatamente asociado a una separación original: el. comienzo del saber es el comienzo de la exigencia de una dimensión exterior en que se concretice esa separación entre interioridad y exterioridad que supone la conciencia. En la filosofía de Emmanuel Levinas, conciencia y habitación son descritos como aspectos indisociables en la constitución del sujeto: la intimidad de la conciencia se concretiza o tiene una dimensión exterior en la morada. El sujeto, "simultáneamente afuera y adentro, va hacia afuera a partir de una intimidad. Por otra parte, esta intimidad se abre en una casa, que se sitúa en ese afuera. La morada, como edificación, pertenece, en efecto al mundo de los objetos. Pero esa pertenencia no anula el alcance del hecho de que toda consideración de objetos -sean éstos edificaciones- se produce a partir de una morada. Concretamente, la morada no se sitúa en el mundo objetivo, sino que el mundo objetivo se sitúa a partir de la morada" (Levinas, 1982, 163-164). El saber concebido como recogimiento supone un intus, una interioridad. Interioridad que no se manifiesta sólo como una dimensión ideal, sino como separación concreta del sujeto. Decimos que sólo el hombre está, o puede, estar desnudo, y esa distinción supone ya esa separación concreta entre una esfera interior y una esfera exterior. El animal no se encuentra, por cierto, vestido; sin embargo, sólo el hombre despojado de su vestimenta puede propiamente estar desnudo. Desnudo o vestido; desnudo o abrigado, cobijado o a la intemperie, el vestir y la habitación aparecen como grados de una

\footnotetext{
${ }^{3}$ En ese sentido se puede leer la afirmación de J-L Nancy "la fe cristiana es por sí misma experiencia de su historia, la experiencia de un plan seguido por Dios para el logro de la salvación" al punto que "el logro de la salvación se hace indisociable de la historia humana, se convierte en la historia humana como tal, en la Historia". Jean-Luc Nancy, La déconstruction du Christianisme, en Les Etudes Philosophiques, n 4, Paris, 1998
} 
misma condición. Como grados de una desnudez que evoca esa misma separación entre interioridad y exterioridad que, según la imagen mítica, es la consecuencia de nuestro progresivo distanciamiento respecto a la naturaleza y se concretiza en una actividad de mediación como trabajo, producción, o transformación del mundo. En el relato mítico, el hombre en cuanto ser caído, arrojado al mundo abandona la inmediatez de su relación con respecto a la naturaleza y se establece para siempre en su existencia separada, en ruptura con lo que le rodea. La filosofía occidental recoge esa imagen: la existencia humana es comprendida, así, como existencia mediada por el trabajo y la conciencia; lo humano existe en la forma de la mediación que se establece en su relación con el mundo a través de esa conciencia, de ese trabajo (y, por ende, a través de la técnica, del vestido, de la habitación...). ¿Cómo considerar el habitar desde esta tradición? Interioridad y exterioridad surgen, primero, como separación entre conciencia y mundo; sin embargo, el habitar no es un momento segundo, sino una condición primordial en la separación: el surgimiento mismo de la conciencia supone ya la habitación en cuanto interioridad primera: la conciencia es recogimiento en un interior, y el habitar surge como encarnación de la consciencia. Como lo expresa Levinas, ésta remite a una primera habitación, pues "la civilización remite a la encarnación de la conciencia, a la habitación -a la existencia a partir de la intimidad de la casa, concretización primera. La noción misma del sujeto idealista surge de un desconocimiento de ese desbordamiento de la concretización” pues "el recogimiento, obra de separación, se concretiza como existencia en una habitación, como existencia económica. Pues el yo existe al recogerse, refugiándose empíricamente en una casa”. (Levinas, 1992, p. $163)$.

En los albores de la modernidad, Thomas Hobbes constataba que así como el hombre era ya capaz de "construir una casa que durase tanto como sus materiales" también era capaz de construir un sistema político que durase eternamente. Construcción, artificio; sin duda, palabras clave en el pensamiento de Hobbes: pues "mediante el Arte se construye ese Leviatán que llamamos república o Estado" que es como "un hombre artificial" (Hobbes, Leviatán, p. 81). Ella representa la capacidad del hombre moderno de erigir un mundo que supere a la pura naturaleza. El artífice, ya sea el técnico o el artista, hace posible la superación de las calamidades naturales tanto en el orden político como técnico: la política misma es 
ahora concebida como técnica. La separación de la naturaleza es entendida como el progresivo distanciamiento respecto de las necesidades y calamidades naturales. La producción de un mundo artificial, las transformaciones del mundo por medio del trabajo son comprendidos como progresiva humanización, y a la vez, como emancipación progresiva de la humanidad. El progreso mismo es progreso en la separación respecto al mundo natural. Los proyectos de arquitectura de la época moderna intentan establecer una forma de habitar que, suprimiendo las diferencias naturales, ofrezca las mismas posibilidades de existencia en distintos lugares del mundo. La ciudad de Brasilia es sin duda un intento por demostrar al mundo que el Brasil y sus arquitectos superan la exuberancia de la naturaleza y son capaces de construir y reproducir el mismo modo de vida que impera en el mundo desarrollado. La ciudad se construye dando la espalda a la selva, como un símbolo de la definitiva distancia respecto del "estado de naturaleza". Tanto en Chile como en Francia o la India, los proyectos modernistas, de Le Corbusier, Costa, Niemeyer u otros, reproducen y globalizan las soluciones universales en nombre del progreso y la emancipación de la humanidad.

Ciertamente, la naturaleza es continua reproducción cíclica -generación y corrupción, como lo llama Aristóteles en una de sus obras fundamentales. Y esa reproducción puede ser comprendida -así lo hace esa filosofía a lo menos- como continuo retorno de lo idéntico: el cambio, la historia de cualquier relación diferencial que asuman en su existencia las cosas naturales parece ser reabsorbida por la repetición constante de los patrones genéricos, por la continua reaparición de esa impronta específica que constituye esencialmente a los entes.

El Arte de la arquitectura, devenido técnica arquitectónica masiva con la modernidad, pareciera imitar a la naturaleza en su continua reproducción de lo idéntico: el artificio técnico asume conscientemente su tarea como producción en serie: Le Corbusier "Hay que tender al establecimiento del estándar para afrontar el problema de la perfección”

"La gran Industria debe preocuparse de la edificación y establecer en serie los elementos de la casa"

"Hay que crear el estado de espíritu de la serie"

"el estado de espíritu de construir casas en serie"

"el estado de espíritu de habitar casas en serie"

“el estado de espíritu de concebir casas en serie” (Le Corbusier, 1980, p. 31) 
La producción arquitectónica serial parece superponerse a la naturaleza, superarla: el proyecto arquitectónico moderno ha podido ser concebido como parte del proyecto emancipatorio. Emancipación que es también emancipación de ese ciclo natural: si la arquitectura moderna sustituye o superpone a la reproducción natural de la naturaleza la producción serial de las obras técnico arquitectónicas, lo hace pensándose a sí misma como superación de lo natural: la superposición de lo técnico arquitectónico se asume como la solución a las carencias, las insuficiencias y las calamidades que el hombre moderno no se cansa de descubrir en el entorno natural: la naturaleza es, al parecer, puro defecto: siempre falta un instrumento, siempre detectamos la necesidad de la producción de una prótesis, de un abrigo, de un suplemento que corrija el aspecto deficitario, incompleto, que reviste nuestro mundo ante la mirada moderna. Y es que la técnica moderna, y con ella la moderna técnica arquitectónica, no asume sólo un carácter serial, sino, al mismo tiempo, progresivo: la técnica no promete sólo mejorar nuestra condición respecto a la naturaleza; promete también abrirnos el camino hacia una continua mejora, hacia un perfeccionamiento continuo. Pues si la técnica surge desde el inicio, tanto en la antigüedad como en la época medieval, como suplemento, como superación de la naturaleza en sus defectos, la técnica moderna parece asumir, al mismo tiempo, la necesidad de superar progresivamente esas mismas soluciones que se han ideado como suplemento de esa carencia fundamental en que se origina, desde la partida, la empresa técnica: la técnica arquitectónica serial moderna re-produce habitaciones en serie, reproduce el estado de espíritu de construir casas en serie, como lo dice Le Corbusier, pero, al mismo tiempo, no puede sino intentar cada vez superarse a sí misma. Si la arquitectura moderna parte de la constatación de un déficit en nuestra natural manera de habitar, ella constata, al mismo tiempo, que ese déficit parece no tener fin: la arquitectura moderna, como la técnica moderna, es la promesa de un progreso infinito en la superación de una existencia que siempre es descubierta como deficitaria. Siempre hay un déficit que suplir, siempre hay carencias, siempre hay una nueva fisura, fragilidades y defectos que se constatan en nuestra existencia y que parecen exigir nuevos implantes, nuevas estructuras y superestructuras que mejoren progresivamente el habitar.

Si la naturaleza ha podido ser descrita como reproducción, como continuo movimiento cíclico, circular, en el que predomina y se impone la repetición de una forma sustancial, 
$\overline{\text { perpetuo retorno a lo idéntico, en la multiplicación técnica, por el contrario, si bien existe }}$ serialidad y reproductibilidad, esa repetición está condenada a sucumbir y ser reemplazada por una nueva serialidad: los artefactos o los productos de la producción técnica están siempre condenados a ser reemplazados por la producción de otras series, otras formas de producción que implican otras formas de reproducción, otras tantas subespecies que rompen la continuidad serial: hachas, teteras, casas, son especies técnicas que a través del tiempo nos reservan la aparición de inimaginables subespecies, pues el tiempo o la temporalidad que rige el proyectar nos asegura esa continua concepción de nuevas formas que sin duda no parece tener fin. Dios creador de la naturaleza. Ese, que puede ser nuestro Dios judeo cristiano o ese Demiurgo hacedor del mundo griego, crea las cosas como un continuo retorno de las formas, que vence todo el trabajo del tiempo, o hace que el tiempo parezca obrar para éstas en ese trabajo. Al contrario, el demiurgo o el pequeño dios artista establece constantemente una ruptura en la continuidad de la serie, multiplicando y subvirtiendo la clasificación de géneros, especies y subespecies. "Porque aun cuando el desarrollo de la genética permita una superación definitiva de la noción de especie, si ésta última ha sido válida y lo es todavía, ello se debe a que, efectivamente, del caballo nace el caballo, y que, a través de un número suficiente de generaciones, Equus caballus es el descendiente real del hiparión. La validez histórica de las reconstrucciones del naturalista tiene, en último análisis, la garantía del lazo biológico de la reproducción. Un hacha, en cambio, no engendra nunca otra hacha; entre dos útiles idénticos, o entre dos diferentes que posean una forma tan semejante como se quiera, hay y habrá siempre una discontinuidad radical, derivada del hecho de que uno no ha nacido del otro, sino que cada uno de ellos ha nacido de un sistema de representaciones..." (LeviStrauss, 2003, p. 13)

Cada nueva obra de arte es en cierta manera una especie por sí misma que se afirma en su singularidad. La modernidad supone, sin embargo, una alteración fundamental en ese mismo mecanismo de reproducción serial, acelerando progresivamente esa multiplicación de las formas que rigen la producción de las series: Qué es el cambio de los 'modos de producción' sino un cambio de 'formas de producción', cuya continuidad parece seguir en principio reglas -reglas no naturales, quizás reglas históricas, que corresponderían a una lógica del cambio de formas. Esa es, por lo menos, una de las interpretaciones que acompañan esa modernidad: 
así, la desaparición de una forma técnica es la ruptura de la cadena de reproducción identitaria de una especie; sin embargo, el cambio de forma, la sustitución de esa forma de producción por otra dejaría también descubrir una regularidad, una regularidad en los cambios de forma que finalmente reintegran esos sucesivos cambios de las formas de producción serial en la unicidad de un desarrollo teleológico: cada cambio de forma significaría una superación, un paso más en el camino de la constitución de algo, de algo que para ser ese algo necesita de ese cambio de forma como de las etapas de su desarrollo. Esa lectura permite descubrir en esa continua sustitución de las formas de producción un mecanismo emancipatorio: la sustitución de una forma por otra comprende una continua superación. Cierto, los ciclos naturales de producción y reproducción se distinguieron siempre de los ciclos de producción técnica, artística o arquitectónica.

Hoy en día, parece llegada la hora en que desaparece el optimismo no sólo respecto a la creación de un mundo artificial y a la universalidad de las soluciones técnicas y arquitectónicas, sino también en relación a la idea misma de emancipación que caracterizara a la modernidad y su concepción de la Historia: la puesta en cuestión del proyecto moderno es al menos una puesta en cuestión de la posibilidad del concepto que asociaba producción, construcción, emancipación y progreso.

El pensamiento de Heidegger es uno de los primeros en poner en cuestión el carácter específico que asume la técnica moderna, como explotación que encubre o vela toda posibilidad de un habitar propio al imponer un ser único a las cosas, provocar la naturaleza, emplazándola en cuanto fuente de energía posible:

El desocultar imperante en la técnica moderna es una provocación que pone a la naturaleza en la exigencia de liberar energías, que en cuanto tales puedan ser explotadas y acumuladas. Pero ¿no vale esto también para el antiguo molino de viento? No. Sus aspas giran, ciertamente, en el viento, a cuyo soplar quedan inmediatamente entregadas. Pero el molino de viento no abre las energías de las corrientes de aire para acumularlas. Por el contrario, una región es provocada a la extracción del carbón y minerales. La tierra se desoculta ahora como región carbonífera. De otra manera aparece el campo que el campesino anteriormente 
labraba, en donde labrar aún quiere decir cuidar y cultivar. El hacer del campesino no provoca el campo. En el sembrar las simientes, abandona él la siembra a las fuerzas del crecimiento y cuida su germinación. Entretanto, la labranza del campo ha caído en la resaca de otro modo de labrar, que pone a la naturaleza. La pone en el sentido de la provocación. El campo es ahora industria motorizada de la alimentación. La agricultura es ahora industria mecanizada de la alimentación. Al aire se lo emplaza a que dé nitrógeno, al suelo a que dé minerales, al mineral a que dé, por ejemplo, uranio, a éste a que dé energía atómica, que puede ser desatada para la destrucción o para la utilización pacífica." (Heidegger, 1997, 123-124).

Para Jean-François Lyotard "el desarrollo de las tecno ciencias se ha convertido en un modo de aumentar el malestar, no de reducirlo. Ya no podemos más llamar progreso a ese desarrollo, que parece continuar por sí solo, en virtud de una fuerza o motricidad autónoma, independiente de nosotros. No responde a las exigencias que formula el hombre. Por el contrario, las entidades humanas, individuales o sociales, parecen ser siempre desestabilizadas por el resultado del desarrollo y sus consecuencias. Entiendo por ello no sólo los resultados materiales, sino también intelectuales y mentales. Podemos decir que la humanidad se encuentra en condición de correr tras el proceso de acumulación de nuevos objetos de práctica y pensamiento.” Esa crítica supone una nueva consideración del tiempo: así, "el post del postmodernismo es entendido aquí en el sentido de una simple sucesión, de una secuencia diacrónica de períodos en los que cada uno es por sí mismo claramente identificable. El post indica algo así como una conversión: una nueva dirección después de la precedente." (Lyotard, 1988, p. 177). Pues "la idea de una cronología lineal es totalmente moderna. Pertenece a la vez al cristianismo, al cartesianismo, al jacobinismo: puesto que inauguramos algo completamente nuevo, debemos poner las agujas del reloj en el punto cero. La idea misma de modernidad es correlativa del principio según el cual es posible y necesario romper con la tradición e instaurar una manera de vivir y de pensar absolutamente nueva" (Lyotard, 1988, 114-115). Esa misma concepción postmoderna se expresaría en la arquitectura, en cuanto ésta asume ese escepticismo respecto a la posibilidad de elaboración de un proyecto global de emancipación de la humanidad: los fundamentos mismos de los proyectos emancipatorios, la lógica que preside su ordenación y el orden de las formas que 
impone su geometrización esconden en el proyecto moderno ya un proyecto de dominio y hegemonía. ${ }^{4}$

Ya en el pensamiento de Levi-Strauss encontrábamos la distinción entre la razón moderna occidental, en tanto "cultura del rendimiento" y el "pensamiento salvaje". La crítica que dirige Levi-Strauss al positivismo puede hacerse extensiva a los distintos pensamientos de la emancipación, en cuanto se dirige al concepto mismo de Historia que predomina en la cultura occidental: "Sin duda, Comte asigna al pensamiento salvaje un período de la historia -edades del fetichismo y del politeísmo, que no es, para nosotros, el pensamiento de los salvajes, ni el de una humanidad primitiva o arcaica, sino el pensamiento en estado salvaje, distinto del pensamiento cultivado o domesticado con vistas a obtener un rendimiento. Este apareció en algunos puntos del globo y en algunos momentos de la historia, y es natural que Comte, privado de informaciones etnográficas (y del sentido etnográfico, que sólo la recolección y la manipulación de informaciones de ese tipo permiten adquirir) haya captado el primero en su forma retrospectiva como un modo de actividad anterior al otro. Hoy comprendemos mejor que los dos pueden coexistir y compenetrarse, como pueden (al menos de derecho) coexistir y cruzarse especies naturales, unas en estado salvaje, y otras tal como la agricultura o la domesticación las han transformado, aunque, por el hecho mismo de su desarrollo, la existencia de éstas amenaza con extinguir a las otras" (Levy-Strauss, 1997, p. 315). Aún en nuestra sociedad, dirá Levi-Strauss, subsiste ese pensamiento indómito, que escapa a la cultura del rendimiento, confinado en el lenguaje del arte: "tanto si lo deplora uno como si se alegra de ello conocemos todavía zonas en las que el pensamiento salvaje, como las especies salvajes, se encuentra relativamente protegido: tal es el caso del arte, al que nuestra

\footnotetext{
4 “Según Portoghesi, la ruptura postmoderna consiste en la abrogación de la hegemonía acordada a la geometría euclidiana tal como fue sublimada, por ejemplo, en la poética plástica de "Stijl". Para Gregotti, la diferencia modernismo/postmodernismo se caracteriza más bien por otro rasgo, la desaparición del estrecho lazo que asociaba el proyecto arquitectural moderno con la idea de una realización progresiva de la emancipación social e individual a escala de la humanidad. La arquitectura postmoderna se encuentra condenada a engendrar una serie de pequeñas modificaciones en un espacio que ha heredado de la modernidad, y a abandonar la reconstrucción global del espacio habitado por la humanidad. En ese sentido, la perspectiva se encuentra abierta sobre un vasto paisaje: no hay ya un horizonte de universalidad, de universalización o emancipación general que se ofrezca a los ojos del hombre postmoderno, en particular del arquitecto. La desaparición de la Idea de progreso a través de la racionalidad y la libertad explicarían cierto "tono", estilo o modo específico de la arquitectura postmoderna. Yo diría: una especie de bricolage; la abundancia de citas arrancadas de estilos o períodos anteriores, clásicos o modernos; la poca consideración que se muestra por el entorno, etc.” Lyotard, Ibíd., pp. 113-114.
} 
civilización reconoce la posición de parque nacional, con todas las ventajas e inconvenientes que trae consigo una fórmula tan artificial.” (Levi-Strauss, 1997, p. 315)

Las críticas a la modernidad que han podido ser formuladas hasta hoy ponen en cuestión cierta concepción del tiempo y de la historia. Al punto que podemos preguntarnos hoy por la por la posibilidad de que aquello mismo que llamamos obra o creación, o simplemente trabajo humano, pueda contener algo más que alienación: preguntarnos si la obra del hombre -a través de esa historia, la producción y transformación del mundo, la arquitectura misma que heredamos como proyecto- es producto de una Humanidad que, imponiendo su subjetividad, se eleva por encima de la naturaleza, obra semi divina de los elegidos que a través de su creación se hacen a sí mismos como dioses, o bien es prótesis, muleta, suplemento y remedio contra el dolor, excedencia dislocada del ser, excrecencia de un ser enfermo e inadaptado, incapaz de subsistir de otro modo que en ruptura con el mundo, superponiendo infinitas capas de artificio sólo condenadas a convertirse en acumulación de desechos, en detritus, como el fruto de una anomalía fundamental.

\section{Referencias bibliográficas}

Heidegger M. (1997), La pregunta por la técnica, en Filosofía, Ciencia y Técnica, Santiago de Chile, Editorial Universitaria.

Hobbes T. (2004), Leviathan, Penguin Classics, London. La traducción es nuestra.

Le Corbusier (1980), “L’esprit nouveau”, en Modulor, Poseidòn, Barcelona.

Levi-Strauss C. (1997), El pensamiento salvaje, F.C.E. Bogotá. (1985), Anthropologie structurale, Agora, Paris, 1985. La traducción es nuestra.

Levinas E. (1992), Totalité et infini, Paris, Fayard. La traducción es nuestra.

Lyotard J. F. (1988), "Nota sobre el sentido de post", en Le postmoderne expliqué aux enfants, Paris, Galilée. La traducción es nuestra.

Nancy J. L. (1988), La deconstrucción del cristianismo, revista Les Etudes Philosophiques, $\mathrm{N}^{\mathrm{o}} 4$, Paris. La traducción es nuestra. 
